\title{
From cell-surface receptors to higher learning: A whole world of experience
}

\author{
Draft: Do not cite or distribute without permission
}

\author{
Karola Stotz \\ Australian Research Fellow, Department of Philosophy, University of Sydney, NSW \\ 2006, Australia \\ karola.stotz@gmail.com \\ Colin Allen \\ History and Philosophy of Science and Cognitive Science Program, Indiana University, \\ Bloomington, IN 47405 \\ colallen@indiana.edu
}

\begin{abstract}
:
In the last decade it has become en vogue for cognitive comparative psychologists to study animal behavior in an 'integrated' fashion to account for both the 'innate' and the 'acquired'. We will argue that these studies, instead of really integrating the concepts of 'nature' and 'nurture', rather cement this old dichotomy. They combine empty nativist interpretation of behavior systems with blatantly environmentalist explanations of learning. We identify the main culprit as the failure to take development seriously. While in some areas of biology interest in the relationship between behavior and development has surged through topics such as extragenetic inheritance, niche construction, and phenotypic plasticity, this has gone almost completely unnoticed in the study of animal behavior in comparative psychology, and is frequently ignored in ethology too. The main aims of this paper are to clarify the relationship between the concepts of learning, experience, and development, and to investigate whether and how all three concepts can be usefully deployed in the study of animal behavior. This will require the full integration of the psychological study of behavior into biology, and of the idea of learning into a wider concept of experience. We lay out how, in a systems view of development, learning may just appear as one among many processes in which experience influences behavior. This new synthesis should help to overcome the age-old dualism between innate and acquired. It thereby opens up the possibility of developing scientifically more fruitful distinctions.
\end{abstract}

\section{Introduction}

Animal behavior has been the contested subject of study between two quite distinct disciplines. For several decades in the middle of the last century the ethological tradition in Europe and the psychological tradition in America fought an intellectual war in whose 
center stood the 'instinct' concept (Griffiths 2004). Tinbergen's acceptance of some of the major criticisms of this concept and then Robert Hinde's remaking of ethology in the sixties officially put an end to the war. Nevertheless, both traditions remained largely separated in the fields of behavioral ecology, sociobiology, evolutionary psychology and cognitive ethology on the one hand and comparative psychology on the other. While the former disciplines were mainly interested in the species-typical behavior of animals in their natural habitat and the evolutionary contexts in which different behavioral phenotypes are selected, the latter focused on general mechanisms of learning in tightly controlled conditions. The main differences between the two fields were their methodology, field studies versus laboratory experiments, and their subject of study, innate versus acquired behavior. In the last decade it has become en vogue for cognitive comparative psychologists to study animal behavior in an 'integrated' fashion: While the acquisition of knowledge remains the primary target of scientifically rigorous investigation, the natural habitat and evolutionary endowment of the organism are taken into account, and explanations are sought at both the behavioral and the cognitive level.

We will argue that these studies, instead of really integrating the concepts of 'nature' and 'nurture', rather cement this old dichotomy. They combine empty nativist interpretation of behavior systems with blatantly environmentalist explanations of learning, based on the assumption that 'the innate must be there before learning begins'. The main culprit, identified by Lehrman more than half a century ago, is the failure to really take development seriously if it is taken into account at all (Lehrman 1953). While in some areas of biology interest in the relationship between behavior and development has surged through topics such as parental effects, extragenetic inheritance, and phenotypic plasticity, this has gone almost completely unnoticed in the study of animal behavior in comparative psychology, and is frequently ignored in ethology too. Reasons for this may include the traditional focus on the functions of behavior in its species-specific form in adult animals, a preformationist or deterministic conception of development, and generally the separation of psychology from biology. In psychology the process of learning is set against the maturational unfolding of the young to the adult instead of being understood as one part of the wide range of processes by which an organism 
integrates environmental information, all of which are part and parcel of behavioral development.

Studies by developmental psychobiologists and some social neuroscientists, to be described further below, show that the generalizations of the previous paragraph are not universally true (Michel and Moore 1995; Cacioppo and Berntson 2004). While some focus on naturally occurring individual differences, others study the necessity of individual experience in explaining a species-typical outcome. Social neuroscience is a relatively new research field that examines the role of the central nervous system in the development and maintenance of social behaviors. Meaney and colleagues have studied how individual differences in maternal care in rats can alter an offspring's neural development, as well as its ability to cope with stress later in life. The team elucidates the molecular mechanisms that modify the expression of genes regulating hippocampal synaptic development as well as behavioral and neuroendocrine responses to stress. (Meaney 2001). Aside from these promising research areas, the failure to pay sufficient attention to developmental questions in the origin of behavior is widespread. Here we provide a few prominent examples of this failure from comparative psychology, particularly accounts of the relationship between humans and their closest relative.

In a recent paper Penn, Holyoak, and Povinelli urge that discontinuities between humans and apes are more significant than is typically admitted by primatologists whom they accuse of especially ignoring the higher-order, systematic, relational capabilities of human users of physical symbol systems (Penn, Holyoak, and Povinelli 2008). However, just as with most of traditional cognitive science, they confound cultural symbolic achievements with individual cognitive competencies. Their argument for a large discontinuity between human and non-human primates rests on a hybrid symbolicconnectionist model of cognition which does not provide any explicit role for learning, and only a diminished role for development, as is commonly the case with models already couched in "the currency of symbol manipulation" (McGonigle and Chalmers 2001). Such an approach, polemically dubbed the 'Rational Bubble' stance, belongs to a class of models that have in recent years come under increasing criticism from those 
taking an embodied stance as a quite unrealistic model of cognitive growth (McGonigle and Chalmers 2008).

The difficulty of being fully sensitized to the developmental dimension of cognition is highlighted by another example. Tomasello and collaborators have proposed the 'Cultural Intelligence Hypothesis' (CIH) about the particular role that 'ultra-social' learning through cultural participation, instruction, and formal schooling played in the development and evolution of human cognition (Herrmann et al. 2007; see also Tomasello 1999). The CIH gains support from an empirical study that compared the capacities of children with apes. But although the $\mathrm{CIH}$ is in large part a developmental hypothesis, the investigators neglected to address this developmental dimension in their experimental design. The apes used in this study, though compared with human children of all the same age of $2 \frac{1}{2}$ years old, were of a wide range of adult ages. Further, no information is provided on the rearing conditions, hence enculturated status, of the apes. This is quite surprising from a laboratory that has also put forward the 'Enculturation Hypothesis', an epigenetic model of the effect of human rearing on the cognitive development of apes. Research reports supporting this hypothesis, and later reports that led the investigators to believe that even 'normal' apes are socially more competent than originally thought, stand in stark contrast to the findings that support the $\mathrm{CIH}$ (Call and Tomasello 1998; see Tomasello and Call 2004 for further references).

These examples raise three worries: 1. Many skills that are tested in stand-alone experiments have developmental dimensions that most test designs miss or deliberately ignore. 2. There may be a range of tasks that younger ages generally perform better than adults. 3. One needs the comparative context of the test results in order to interpret them properly, so for instance testing untrained and unenculturated apes against enculturated apes on the one hands and humans on the other, and sampling all three groups at different but developmentally comparable ages, would be necessary. An experiment testing three pairs of mother and offspring chimpanzees against university students in a memory task provides a case in point (Inouea and Matsuzawa 2007). The young chimps far outcompeted human adults, but also their mothers. This result suggests a developmental 
component within the tested memory faculty rather than a species difference. In order to test this, a superior experimental design would have included human children in the study. It is important, however, to recognize that different aspects of development may proceed at different rates in different species (e.g. Gácsi et al. Forthcoming), thus it is not ever possible to perfectly match developmental ages between two species.

Much of comparative psychology takes place against an assumed background of animal learning theory, which treats associative learning mechanisms as strongly conserved across vertebrate species. On this conception, the capacity for learning is merely a product of development, rather than a process within development. Our main aim in this paper is to forge a closer relationship between the concepts of learning, experience, and development, and to investigate whether and how both concepts can be usefully deployed in the study of (human and non-human) animal behavior. This will require a biologically informed comparative psychology, and the formulation of a concept of 'experience' that includes all aspects of environmental stimuli that lead to long-term, adaptive changes of behavior, including 'learning' in its original sense. In other words, our use of the concept experience is not limited to sensory processing but includes a quite heterogeneous mix of environmental resources influencing the system's behavior.

This understanding follows Schneirla's original definition of experience, emphasized by his student Daniel Lehrman: "the contribution to development of the effects of stimulation from all available sources (external and internal), including their functional trace effects surviving from earlier development (Schneirla 1957, 1966).” Within this wide range of processes "learning is only a relatively small part" (Lehrman 1970, 30). To take this really on board one needs to acknowledge that physiological regulation and behavior cannot be as sharply separated, since their underlying mechanisms do not necessarily belong to distinctly different classes, even more so in early development. Introducing the concept of experience is not another way of saying that all behavior is learned, but a vehicle to bring home the inadequacy of the distinction between innate and acquired. 
In section 2 we will identify and criticize two received views of development, predeterminism and the so-called Modern Consensus. In their place we propose an 'epigenetic systems view of development' encompassing the organism in its developmental niche, which takes seriously the idea that all traits, even those conceived of as 'innate', have to develop out of a single-cell state through the interaction between genetic and non-genetic (experiential) resources of development. The message of this section will not only be that one should dispense with old dichotomies when attempting to explain the development of a phenotypic trait, physiological and behavioral. We go further to claim that the different dichotomies, such as innate-acquired or nature-nurture, are not only inappropriate labels in themselves, mere placeholders for a real causal analyses of development; they also do not, as is commonly held, map neatly onto each other: genes do not equal nature, nor does environment stand for nurture. As a matter of fact, no developmental factor corresponds to either nature or nurture. Instead we want to promote an understanding of nature that shifts attention from allegedly fixed genetic causes to the range of natural phenotypic outcomes, and a conception of nurture as the normal developmental processes leading to those outcomes.

Section 3 will look at several conceptions of learning and cognition in psychology and how they are employed in the study of a wide range of organisms. We place an emphasis on simple systems approaches, such as invertebrates, the spinal cord, single cell organisms, and even eukaryotic cells in a multicellular organism, in which the boundary between learning and other kinds of experience becomes fluid. This is an important step toward reconciling accounts of learning with our conception of epigenetic development that necessarily includes some form of experience in the construction of any physiological or behavioral trait.

Section 4 will attempt a synthesis of the two concepts. We lay out how, in a systems view of development, learning may appear as just one among many processes in which the experience of an environmental input generates an appropriate response and hence influences the behavioral phenotype. This will be followed by a discussion of the concept of ontogenetic niche and the kinds of experience it affords. We also discuss how such a 
new synthesis should help to overcome the age-old dualism between innate and acquired and thereby opens up the possibility of developing scientifically more fruitful distinctions. Finally, section 5 summarizes the argument of the paper and draws some conclusions for philosophy.

\section{Taking Development seriously}

Scientific understanding of the nature and history of living things, including their cognitive capacities and behavioral phenotype, depends crucially on having a proper understanding of the most basic of biological processes that brought them about: development. Since ancient times this process has captured the imagination of scholars but has eluded a satisfactory explanation or consistent framework until today. The main problem in the interpretation of development has from the beginning been the question of whether organisms merely unfold or mature out of something already formed from the beginning, or whether they emerge as something qualitatively novel from an undifferentiated and unformed state. Despite being declared dead many times, this debate is alive and well today in the dichotomy of nature, or genetic determinism, and nurture, or environmental plasticity.

\section{Preformationism, epigenesis, and the Modern Consensus}

Preformationism, one of the ancient conceptions of development that goes back to Hippocrates, held that the organism is formed from the beginning, with the developmental process bringing about no qualitative change but merely unfolding. Some preformationists considered gametes as minuscule organisms, tiny homunculi they actually claimed to make out under the microscope, needing just to grow or unfold themselves. In the $19^{\text {th }}$ century, preformationism was replaced by predeterminism, the idea that development consists of an orderly progression of qualitative change to a predetermined endpoint. According to the preformationist, environmental factors are understood as a mere background of supportive and permissive factors. In this view, behavior appears as an 'epiphenomenon of neural maturation' (Gottlieb 2001). 
The main rival to the preformationist and predeterminist conceptions was the idea of epigenesis that dates back to Aristotle and maintained that development is a contingent process of differentiation out of a homogeneous and undifferentiated state with no predetermined endpoint. Without an easy preformationist interpretation for the seemingly orderly progression of developmental events, however, epigenesists needed to appeal to either internal or external teleological or vital forces. Due to the mechanistic spirit of embryology in the late $19^{\text {th }}$ century vitalism, and therefore epigenesis, has fallen in deep disregard (Robert 2004; Maienschein 2005). However, one should understand both positions as necessarily ill-informed attempts at a materialist and scientific explanation of development. The preformationists' desire to conceive of organisms fully as the result of known physical forces required the 'auxiliary' assumption that cells within the organism existed in a preformed and god-given state. Epigenesists conceived of development without this deistic assumption, and hence needed to propose an unknown (but not necessarily mystical) vitalist force acting on biological objects, comparable to Newton's forces that applied to physical objects. Arguably, the early 20th century with its transmission genetics vindicated the former position, while the dawn of postgenomic biology and the science of self-organization and complexity brought the new preformationism into disrepute and vindicated the epigenetic position.

The Century of the gene (Keller 2000) brought about a new and more sophisticated preformationism, which replaced 'preformation' with 'information' encoded in the genome needed to make an organism. True to the spirit of today's interactionism the mainstream modern consensus can be "standardly construed as the epigenesis of something preformed in the DNA" (Robert 2004, 34). Instead of avoiding the unscientific dangers of both preformation and vitalist epigenesis, however, it rests ultimately on an unscientific conception of gene and gene action. In our view, the 'genetic program' with its evasion of the responsibility to give a causal-mechanistic explanation of the problem of development is tantamount to a materialized vital force. Hence the new conception of genes that 'program' outcomes is in this sense equivalent to an 'animistic' predeterminism. 
In its place we want to promote what others have called 'probabilistic, contingent, or constitutive epigenesis', a systems view that understands development as an epigenetic process of qualitative change based on the orderly emergence of novel behavioral traits during development without recourse to a preexisting plan. The contingent nature of development, due to the immense importance of experiential factors at all stages of development, from the regulation of gene expression to the learning of tool use or language, demands that we take it seriously (Gottlieb 2001; Michel and Moore 1995; Oyama, Griffiths, and Gray 2001; Robert 2004).

\section{Beyond Nature and Nurture}

One of the foremost aims of a new conception of development is to challenge the widely held view that the physiological or behavioral phenotype derives from either nature or nurture, or from both nature and nature. Both the exclusive and the additive models make no biological sense whatsoever, since no genetic factor can properly be studied independent of, or just in addition to, the environment. The same is true for the environment, which in itself is a concept that includes a wide variety of very different causes and factors, from the genomic environment of a gene, over its chromatin packaging and cellular context, up to ecological, social and cultural influences on the whole organism. So-called innate traits may also be effects of epigenetic factors which are reliably reproduced with the help of ontogenetic niche construction. To resolve the nature-nurture debate a new view of development is needed to address several distinct but related sub-problems: 1) It needs to systematically question preconceptions of 'explanatory' categories of behavior, such as innate, acquired, genetically determined or programmed, which obscure the necessity of investigating developmental processes in order to gain insight into the actual mechanisms of behavior. In addition such preconceptions are prone to committing the 'phylogenetic fallacy', which conflates evolutionary and developmental explanations. 2) Such a new account needs to promote a new understanding of the nature of inheritance, which includes maternal effects on gene expression, epigenetic factors such as genetic imprinting, behavioral, cultural and symbolic inheritance systems, and ontogenetic niche construction. 3) A realistic view of 
gene action and activation is of pivotal importance to a theory of development since it helps to distinguish between explanations of the role of genes in development on the one hand and of the complete process of development on the other. 4) A new epigenetic understanding of development should ultimately resolve the dichotomy between preformationism and epigenesis, and between 'maturation' and 'learning'. These four aims are preconditions for the integration of the concepts of 'development' and 'learning' in biological and psychological research into behavior and cognition.

\section{Explanatory categories of behavior}

The main problem with allegedly explanatory categories of behavior such as instinctive or learned, is that they effectively suspend further investigations into the real ontogenetic causes of a behavior. They do this by their very nature of purporting to explain while actually merely labeling the phenomenon. After careful and often arduous empirical investigation, all apparently 'innate' processes operating to regulate behavior have turned out to involve epigenetic or experiential factors (Blumberg 2005). As Griffiths has argued, the vernacular concept of innateness can imply three different and unrelated things, namely the developmental fixity (non-involvement of experience), speciestypicality, or adaptedness of a trait (Griffiths 2002). All of them are standardly equated with an underlying genetic determination.

Besides wanting to argue against the existence of any genetically determined trait, we maintain that a deeper investigation of all three characteristics is able to show their relative independence of each other. Evolutionary adaptations need not be developmentally fixed, independent of life experience, and hard to change, but can instead be phenotypically plastic, as is the case with many highly environmentally sensitive polyphenisms, distinct phenotypes that are elicited by different environmental conditions (see below section 4). Nor do adaptations need to be species-typical or universal. They can result from frequency-dependent selection, where the trait is only adaptive if a certain percentage of the population carries it. Species-typical or universal traits are not necessarily the result of natural selection but can be dictated by strong physical or developmental constraints that render them hard or even impossible to 
change. This has been shown by many examples uncovered by the new 'physicoevolutionary' approach, or by research into the homologies of organisms (Newman 2003; Gilbert 2003). Last but not least, universality need not be and often is not due to the developmental fixity or experience-independence of a trait. It may be and often is due to the reliable availability of certain experiences to which the organism must be exposed to develop a trait. Song learning in many bird species is a case in point. In some species of birds, such as the Brown-headed Cowbird, all birds belonging to a population sing the same song (while in many others the songs of individuals may differ substantially, such as in the Australian Lyre bird, or the Indian Common Mynah). While instances of uniform songs were once taken as support for the genetic determination of song 'learning', we now know that cowbirds have to be exposed to other members of their species in order to acquire their population-specific song. The story in cowbirds, which are nest parasites and are therefore not raised by their own parents or even a member of their own species, is even more complicated and intriguing than with birds which acquire the song from their parents. The details of how they acquire their song need not be described here - it suffices to say that cowbirds nevertheless always learn to sing the particular dialect of the population they belong to because of the reliability with which they meet, recognize and flock with members of their own species and are therefore exposed to the right stimulating experiences during development (West, King, and Duff 1990; Freeberg et al. 2002).

Transgenerational stability need not rely on the faithful transmission of DNA. Natural selection selects for adaptive traits or phenotypes; that is, it selects for outcomes and not for developmental mechanisms. Outcomes always derive from non-linear interactions among a range of diverse developmental resources. Their organization frequently exhibits phenotypic plasticity, a capacity that allows the organism to react adaptively to different environmental conditions (Pigliucci 2001; West-Eberhard 2003; Gilbert and Epel 2009). The stable inheritance of this adaptive phenotype depends on the reliable transmission of all the necessary developmental factors across generations. In other words, phenotypic plasticity relies on a dependable yet flexible 'developmental niche' which is faithfully 
reconstructed by the species, the parent and the organism itself (West and King 1987). The subject of selection is the whole developmental system.

\section{Extragenetic inheritance and developmental niche construction}

The construction of the developmental niche relies heavily on the extragenetic inheritance of developmental resources. This heterogeneous process includes maternal and paternal effects, which cannot be reduced to just the influence of parental genes or RNAs on their offspring, but includes all processes of care for the offspring. These are comprised of imprinting systems, cellular structures, gut organisms, differential provisioning of resources, preference induction (oviposition, imprinting on food, habitat, and mates), and social learning, to name just a few (Jablonka and Lamb 2005; Mousseau and Fox 1998; Maestripieri and Mateo 2009). Ontogenetic niche construction is one way to conceptualize 'extended inheritance'. Inheritance systems have evolved to allow for the transmission of crucial information from parents to offspring. A principled definition of inheritance must include whatever is reliably present in each generation due to the parental generation and necessary to reconstruct the life cycle. We should not single out a particular type of resource as the source of intergenerational stability. A reliably reproduced developmental system is the result of the reliable provision of a wide range of developmental resources necessary to reconstruct the organism's life cycle, of which DNA is just one element. Organisms place DNA into a developmental setting that is always highly characteristic of a lineage and commonly owes much of its structure to the activity of previous generations. Evolution has come up with a wide range of strategies to construct the ontogenetic niche to dependably guide the developmental process.

What all the above cases of inheritance through environment construction have in common is that they make the transmission of crucial information more reliable. Parental activity can facilitate, guide and entrench social learning. While some of the aforementioned mechanisms have at first sight not much in common with the construction of cognitive or epistemic structures, in the latter cases of behavioral, ecological and cultural inheritance the biological shades smoothly into the cognitive. For 
example, the emergence of cognitive capacities for tracking objects that are out of sight depends on the development of motor systems regulating embodied actions such as reaching (Smith and Breazeal 2007 show how cognition emerges out of non-cognitive processes).

West and King were among the first to "Ask not what's inside the genes you inherited, but what your genes are inside of" (West and King 1987, 552). A look at the enormous complexity of gene expression of eukaryotes reveals a very flexible and reactive genome open to many intra-and extra-organismal environmental influences which makes it necessary for organisms to manage aspects of their own ontogenetic environment. It is not which genes you have that has phenotypic consequences, but how they are expressed by the higher order network of gene regulation that controls the time- and tissue dependent expression of genes. There have been repeated attempts to reduce epigenetic mechanisms to the action of inherited or parent-of-origin genes, so that ultimately the real causes are all genetic. This special pleading fails in the light of the discovery that the regulated expression of genes ultimately depends on a host of environmental factors.

\section{Environmental regulation of gene expression}

Genetic activity is involved in all biological processes, but so are non-genetic factors. Explanations listing only interacting genes are biased at best and relatively vacuous at worst. More informative explanations give an account of why and how certain genes are expressed at a particular place and time, an account that necessarily includes a range of very specific additional factors, including environmental signals.

Postgenomic biology has brought with it a new conception from the active gene to the reactive genome that is activated and regulated by cellular processes that include signals from the internal and external environment (Stotz 2006). This is not the place to report the details now available on the mind-numbing complexities of the expression of genes during development, instead a few central ideas should suffice. The last decade of genome-sequencing has revealed the paradox that the complexity of organism is not related to its number of genes. Instead, it seems to be related to the complexity of the 
expression of a limited number of coding sequences. In the last two decades development has become equated with differential gene expression, but what is often forgotten in this definition is the complex network of other molecules (such as proteins and metabolites), cellular structures, 3-dimensional cellular assemblages and other higher-level structures that control or are otherwise involved not only in this differential expression of genes but in a wide range of other developmental processes decoupled from the direct influence of DNA sequences.

These mechanisms do not just control when genes are switched on and off, but also which parts of the DNA sequence will be transcribed, spliced and edited in complicated ways, and translated at specific rates. Often the particular mixture of gene products and their interacting cellular signaling factors are referred to as the cellular code. The cytoplasmic chemical gradients, plus the maternal gene products, inherited with the mother's egg, give this process a head start, but the mother's control over her progenies' genes and their environment does not stop there. Chemical processes in the womb, and after birth, rearing practices such as the differential licking of pups by rat mothers, continue to influence (neurological) development through gene expression levels (Moore 1984; Meaney 2001). Parental chemical modification of the DNA influences the expression of genes throughout the offspring's life. This imprinting system is often called the histone, chromatin or epigenetic code.

Genes have an important role in development, but their role can be properly understood only within the larger system that holds controlling influence over them. Jason Scott Robert summarizes this attitude thus:

To take development seriously is to take development as our primary explanandum, to resist the substitution of genetic metaphors for developmental mechanisms ... The translation of embryology's hard problem (how a specific organism arises from a single, relatively homogenous cell) into a problem about gene action and activation generates explanations at the level of genes; but these explanations solve (or, rather, begin to solve) the subsidiary problem of the role of genes in development, not the 
problem of development as such.... There is indeed good reason to believe that genetics reduces to development, and not the other way around. (Robert 2004, 22)

\section{A new epigenesis}

What a new account of development really has to accomplish is not just to go beyond these vexed dichotomies such as innate and learned, but to provide a framework that integrates a complex set of heterogeneous factors into a system of developmental resources all of which are reliably reproduced in succeeding generations of a developmental system but none of which really belong alone to either 'gene', 'organism' or 'environment' (the famous "Triple Helix" of Richard Lewontin 2000). Its contextualization of genes should obviate "even naïve temptations toward gene/environment dichotomies, and ... will open up a very rich area of empirical investigations to examination and conceptualization in developmental-system terms. ... Ultimately, such a view should work towards "overcoming inner/outer dichotomies in favor of self-organizing, causally reciprocal systems of interaction" (Moss 2001, 85). Developmental Systems Theory (DST), an alternative approach to integrating evolution, development and inheritance, provides just such a framework and its conception of development is basically the one promoted in this paper (for a short introduction in its central tenets see Oyama, Griffiths, and Gray 2001).

The important systems features of such a view are the rejection of dichotomous description of behavior in favor of a full analysis in terms of continuing interaction between, and the joint determination by, heterogeneous developmental resources. Learning may be involved but only as part of an overall concept of experience which include less obvious contributions, such as self-stimulation. An important part of such an analysis implies seeing behavior as belonging to the organism's overall anatomical and physiological make-up. A dynamical systems view of locomotor development exemplifies such an approach very well by including the growth of muscles and the infant's strength in an account of behavioral coordination of movement (e.g., Thelen 1995; Spencer et al. 2006). Other important features of a developmental systems account 
are the context sensitivity and developmental contingency of all developmental factors; the distributed control of development upon its heterogeneous resources, and the acknowledgement of the role played by the developmental system to control its further development; extending the idea of inheritance to include other factors than DNA, including factors formerly thought of as 'environmental' or 'experiential' if they are reliably reproduced or 'passed on' to succeeding generations; and last but not least the reconceptualization of development (and evolution) as the interactive construction in a thoroughly epigenetic account of development that "never sidesteps the task of explaining how a developmental outcome is produced" (Oyama, Griffiths, and Gray $2001,4)$. This broad conception of 'epigenetics' is expressed succinctly by Eva Jablonka:

Epigenetics ... focuses on the general organizational principles of developmental systems, on the phenotypic accommodation processes underlying plasticity and canalization, on differentiation and cellular heredity, on learning and memory mechanisms. Epigenetics includes the study of the transmission of subsequent generations of developmentally-derived differences between individuals, thereby acknowledging the developmental aspect of heredity. (Jablonka, pers. comm., cited in Gottlieb 2001)

\section{Reclaiming the Environment}

Such an epigenetic view of development necessitates a new appreciation of the environment, which has been conspicuously absent from the last 100 years of developmental research. The rise of the new science of Entwicklungsmechanik (developmental mechanics) in the late $19^{\text {th }}$ and beginning of the $20^{\text {th }}$ century saw the demise of the anatomical tradition, which due to its evolutionary framework and its methods of observation of developing organisms in their natural context came to be regarded as old-fashioned and unscientific, and mystical ideas of epigenesis were completely rejected. The new mantra of experimentation - with its new methodology of manipulating the animal in controlled laboratory settings - brought the discipline of embryology, now called developmental biology, from the sea shore to the indoors. It is necessary to understand the emerging 'model organism' approach against this 
background. To make the scientist independent from the dictates of seasonal availability and natural variability, laboratories started to breed their own animals, with the goal of making them constantly available and as uniform as possible. This constrained the choice of organism, which "must be selected for the inability of their development to be influenced by specific environmental cues". In other words, "the influence of ... environmental sources of phenotypic diversity were progressively eliminated under the physiological context of embryology" (Gilbert 2003, 88f).

While the physiological tradition favored the whole organism at the expense of the environment, a newly emerging genetics focused on genes at the expense of the organism. Both research traditions discounted and dispensed with the environment, the former the external habitat of the organism and the latter the internal cellular environment of genes and their expression. This shows a parallelism with the contemporaneous and ironically named 'environmental determinism' movement in behavioristic psychology, which, by moving the study of animal behavior and learning into the laboratory, dispensed with both the variety of organisms and their natural habitat in favor of uniform organisms and controlled ('environmental') test conditions.

We contend that ecological validity will be an indispensable factor for studying development, experience and learning. New approaches that call for the investigation of organisms 'in the real world', such as Ecological Developmental Biology (Gilbert 2001; Gilbert and Epel 2009) and Developmental Ecology (West 2003), have inspired a flood of new observations and experiments cementing the influential role of ecology in the study of behavior.

\section{Experience and Learning: from subtle influences to obvious connections}

This section looks at the history and current accounts of research into mechanisms of learning in animals, with an emphasis on simple systems approaches in which the 
boundary between learning and other kinds of experience becomes fluid. This is an important step toward reconciling accounts of learning with our conception of epigenetic development that necessarily includes some form of experience in the construction of any physiological or behavioral trait.

\section{Naked behavior: the loss of internal cognition and the natural environment}

In the 19th century, studies of complex behaviors typically contrasted innate, instinctual behavior with the products of learning and intelligence. But even some pre-Darwinian writers such as Henry Lewis Morgan argued that explanations in terms of instinct were vacuous because they merely attributed to an unknown material cause what would otherwise be regarded as the product of intelligence (Johnston 2002). Nevertheless, the distinction persisted, and by the late 19th century the concepts of instinct and intelligence were both understood within the general framework of evolutionary biology. Both notions remained controversial even within that framework. Comparative psychologists, exemplified by Conway Lloyd Morgan, struggled with the question of how to deal with the subjective aspects of intelligence in a rigorous experimental fashion. At the same time, earlier experimental work on instinctive behavior was called into question. For instance, T. Mann Jones and Lloyd Morgan both repeated Douglas Spalding's experiments on feeding behaviors in chicks and found that, contrary to Spalding's conclusion, they involved a learned component (Boakes 1984).

Among the people influenced by Lloyd Morgan was Edward L. Thorndike who, at the beginning of the 20th century, demonstrated just how empirically tractable animal learning could be. Thorndike's experiments with animals escaping "puzzle boxes" showed how to quantify learning in terms of the decrease in time to escape with experience (Thorndike 1911). But Thorndike's methods also initiated a new trend in comparative psychology towards using laboratory setups that had little connection to evolutionary biology. Thorndike tested a range of different species and emphasized the comparative aspects of psychology, but his use of artificial situations and his formulation of general laws of learning such as his famous Law of Effect suggested that species differences were secondary. 
Consequently, with the rise of behaviorism, there came a biologically uninformed environmentalism that regarded the main differences between species as the range of stimuli and reinforcers that could support classical Pavlovian stimulus-stimulus (S-S) conditioning and instrumental response-outcome (R-O) conditioning. Rats, pigeons, but few other species, were intensively studied, because it was assumed that, for the purposes of general learning theory, species differences were relatively unimportant. The behaviorists' categories of S-S and R-O conditioning, and their interpretations of animal behavior, were inseparably linked to, and ultimately defined by, their experimental methods. The terms 'associative' and 'nonassociative' learning are both theoretical abstractions. They are not the result of direct observation; their occurrences are merely inferred. Also, the distinction between single event and related event learning can be seen as rather arbitrary, because it classifies types of learning according to a formal outcome (in a laboratory experiment, no less) rather than considering the underlying mechanisms, which might be quite similar at the neural or molecular levels (Grau and Joynes 2005). This operationalist approach to learning involved little or no regard for the animal's evolutionary or developmental history, its ecological habitat, and its cognitive processes. Or, at least, no explicit regard. For, as William Timberlake has argued, behaviorists' experimental apparatuses were 'tuned' to evolutionary, developmental, and ecological aspects of the organisms studied (Timberlake 2002). Rat learning, but not pigeon learning, was investigated in mazes, and the use of different operant responses, whether pecking or bar pressing, and even subtler aspects of equipment design, such as the size and positioning of levers in a Skinner box, implicitly reflect the experimenters' adaptation of laboratory setups to biological features of the organisms under study.

Comparative psychologists have been paying explicit attention to ecological aspects of learning for well over a decade now (see, e.g., an early review by Shettleworth 1994). The last decade has seen much exciting work on varieties of social and observational learning, and even 'insight' learning, which do not fit the standard models for classical and instrumental conditioning. Nevertheless, the lively debate about these topics has 
been conducted largely in terms of operational definitions and experimental protocols, rather than underlying mechanisms.

Questions about which species are capable of which forms of learning are typically treated as if organisms come to the task as fully-formed representatives of their species. Thus questions about, for example, the imitative capacities of primates rarely take individual development into account (Jones 2005). In fact, it is widely believed on the basis of non-developmental studies that monkeys aren't capable of genuine imitation or are very poor at it while apes are naturally more capable (Byrne 2004). But the importance of development is underscored by experimental findings with human-reared or enculturated apes (mother-raised in captivity with human interaction; nursery-raised; laboratory-trained; and raised within human culture) which gave rise to the strong "enculturation hypothesis" or the weaker "socialization hypothesis" (Call and Tomasello 1996; Tomasello and Call 2004; see also Bering 2004; Furlong, Boose, and Boysen 2008). These explanations provide an epigenetic model of the differential effects of enculturation in human socio-cultural environments on the development of a whole range of capacities in great apes. Among those are many which nativist theories assign to humans alone, such as mental representational capacities and a whole range of social cognitive capacities like intentional understanding, empathy, and 'true imitation'. A recent report describing imitation by Japanese macaques points in the direction of a similar conclusion about the importance of the social context for development of imitative abilities. These macaques were raised in an environment where joint attention with human caregivers was emphasized through the use of gestures such as pointing and the communicative use of eye-gaze, and they subsequently performed well in imitation tasks that macaques typically fail (Kumashiro et al. 2003). Likewise, SavageRumbaugh's investigation of the bonobo Kanzi for such capacities as language comprehension, symbolic communication, and tool use especially when Kanzi is contrasted with unenculturated bonobos in the lab such as P-Suke points to the need for systematic studies of development (but see Savage-Rumbaugh, Fields, and Spircu 2004 for a step in this direction). Lloyd (2004) argues convincingly that many of SavageRumbaugh's critics have seriously underestimated the importance of development. It is, 
for example beside the point to argue that symbolic communication is outside the repertoire of mature, natural-born bonobos. As she puts it, "in order to draw conclusions about potentialities, we must investigate them" (Lloyd 2004, 587). McGonigle \& Chalmers have also criticized psychologists for underestimating the role of learning in cognitive development because their "investigations are rarely followed through from one learning episode to another to assess the cumulative benefits (if any) as a function of the agent's task and life history" (McGonigle and Chalmers 2001).

\section{Simple learning systems}

Neuroscientists and molecular geneticists interested in animal learning have generally adopted the behaviorists' classificatory scheme of S-S (classical Pavlovian) and R-0 (Skinnerian operant) conditioning, but have also attended to 'simpler' forms of singlestimulus learning, such as habituation, dishabituation, and sensitization. Invertebrate organisms, especially leeches and sea slugs, have provided much of our basic understanding of the role of mechanisms of synaptic change in single-stimulus and associative learning (Castellucci et al. 1970; Burrell and Sahley 2001). In most such work, the basic classificatory scheme is methodological and not tied to individual life histories in any detailed way (but see Stopher et al. 1991 for a developmental approach to learning in Aplysia; see section 4 for more details).

Some behavioral neuroscientists have recognized the shortcomings of the operationalism underlying the traditional classification scheme. For instance, Grau \& Joynes argue for a 'neurofunctionalist' approach which seeks to classify learning in terms of both neural mechanisms and adaptive function (Grau and Joynes 2005, 2005). The work done in Grau's lab has shown remarkable learning and plasticity in the rat spinal cord, detached from the rat brain. Their results include long-term effects of nociceptive experience on spinal learning and on its capacity to recover from spinal injury (reviewed in Grau et al. 2006; Allen, Grau, and Meagher 2009). These results suggest that even in the spinal cord, 'experience' has lasting effects on the capacity of neurons to respond adaptively to future environmental conditions. Even better, spinal cords can 'learn to learn' and are 
susceptible to an analog of 'learned helplessness' in which learning is impaired. Despite the obvious developmental significance of these results, organismic development is not an explicit component of their research program.

With hindsight, perhaps no one should have been surprised that the vertebrate spinal cord is a plastic, adaptive system in its own right. After all, invertebrates with fewer neurons than the typical rat spinal cord nevertheless show various forms of learning. The basic cellular mechanisms for learning and memory are highly conserved between invertebrates and vertebrates (Burrell and Sahley 2001) and may even go further back in evolutionary history. For example, the NMDA receptors involved in the synaptic plasticity of neurons use proteins for binding amino acids that are highly conserved from bacteria (Kuryatov et al. 1994).

Even the simplest organisms, bacteria, respond differently to similar configurations of cues in their surroundings on the basis of their specific life experiences. Some of the physical properties of the cellular boundary and the bacteria's complement of cell-surface and internal receptors can react during early growth to environmental factors such as kinds of nutrients, temperature, $\mathrm{pH}$, or concentrations of toxins. Other processes formerly thought to be restricted to more complex organisms have now been described as the norm rather than the exception of prokaryotic behavior. These include the processes of morphogenesis (change in form), cellular differentiation (change in function), aging, communication, and a whole range of group-mediated, cooperative behavior, such as aggregation and sporulation (Lyon 2006; see also Shapiro 2007; Ben-Barak 2008; Zimmer 2008). Shapiro argues that sophisticated information processing capacities in prokaryotic cells warrants a more contemporary view of bacteria as cognitive entities acting in response to sensory inputs. He describes how smart even the smallest living cells can be due to their capacity for meaningful intercellular communication. "Here the term cognitive refers to processes of acquiring and organizing sensory inputs so that they can serve as guides to successful action. The cognitive approach emphasizes the role of information gathering in regulating cellular function" (Shapiro 2007, 812). 
The concept of bacterial learning may thus be no mere philosophical abstraction. But, someone concerned with preserving old distinctions might press us, do bacteria really learn? The answer one gives, of course, depends very much on one's definitions of learning and experience. The question gets a negative answer if learning is restricted to organisms with nervous systems that connect sensory to motor systems, and sensory systems are conservatively defined as specialized organs with specialized receptor cells that connect a specialized cognitive system that has specialized information-transmission cells to the outside world to extract information from the environment for action (or behavior, narrowly defined). However, it possibly gets a positive answer, if 'environment' is understood as the source of a "quite heterogeneous mix of resources called experience" (Moore 2003, 350) extracted by a wide variety of means, and if knowledge and means for behavior derive from more than what is known to the senses. It is definitely 'yes' if cell-surface receptors are subsumed under the rubric of sensory organs (Baker and Stock 2007).

When scientists extend the application of concepts beyond their usual meanings it is right for philosophers and other scientists to be skeptical about whether the extension is warranted or helpful. With the application of concepts such as learning (Tagkopoulos, Liu, and Tavazoie 2008), memory and anticipation (Saigusa et al. 2008), and cognition (Baker and Stock 2007) to single-celled organisms there will, no doubt, be missteps along the way. But not all of these extensions can or should be dismissed on the basis of definitions provided a priori. As biologists have become better and better attuned to the extensive network of interactions between genome and environment, and have gained a greater appreciation of the plasticity of biological systems, the old distinction between development and learning looks increasingly untenable. Almost a century ago, Carmichael made an early attempt at such a synthesis. He wrote that "for in all maturation there is learning; and in all learning there is hereditary maturation" (Carmichael 1925, 260 ; quoted in Johnston 2001). This was ill-conceived because of its poor concept of development as maturation, and its still intact dichotomy between innate and acquired. We believe that it is now possible to make good on the promise of treating 
learning as just one process of experience, and all of them under the general umbrella of development.

\section{Synthesizing development and learning}

There are many ways to reorganize the relationship between two disciplines - here biology and psychology - and their concepts or processes - here development and life versus learning and cognition. Greater appreciation for the biological underpinnings of cognition has led some to propose the equation of life and cognition. Most notably, the 'Santiago' theory of Maturana and Varela makes this explicit: "Living systems are cognitive systems, and living as a process is a process of cognition. This statement is valid for all organisms, with or without a nervous system" (Maturana and Varela 1980, 13). All living organisms, even individual cells, react adaptively to individual experience of external perturbations to maintain their identity. According to this view, cognition, understood as the very basic operation of making a distinction, defines the boundaries of the system and is therefore the activity involved in the self-production (autopoiesis) of living systems. In other words, cognition is not equivalent to, but an indispensable characteristic of, life.

We certainly don't want to propose the fusion of biology and psychology to the extent that both would lose their distinct identities. Rather we promote a biologically informed psychology and a psychologically informed biology. This would require the reciprocal reconciliation, integration and synthesis of their overlapping areas of study, such as the study of behavior, and of their central concepts, among which are development and learning, and as we propose, experience. The study of behavior looks at three interconnected time-scales: evolution, development, and situated behavior. This integration is based on an essential role for biology in a theory of behavior. Central to the project of synthesizing development and learning is to identify cases of epigenetic interaction, both narrowly and widely construed, the role of experience and learning in development, and the role of development in the phenomenon of learning. From a psychobiological perspective, learning appears as a category within an overall framework 
of development as the lifelong, adaptive construction of the phenotype out of the interaction between genes, the organism and its environment. Taking the idea of phenotypic plasticity seriously may lead to a conception of development as a lifelong process of 'learning' or 'acquiring' a mode of living in an environment that is partly constructed by the organism or the previous generation. The other way around, learning understood as the acquisition of novel behavior and gain of knowledge about the environment, becomes synonymous with developing.

\section{The role of Epigenetic mechanisms in development and learning}

Traditionally, behavior has been explained by dissociable influences of genes producing hardwired, innate behavior - and environment - causing acquired, learned behavior. Today we know that the picture is much more complex and intertwined, and that experience, or any kind of environmental inputs in general, achieve their effect on behavior at least in part through the regulation of gene expression in all cells, but particularly the nervous system. Three general mechanisms are employed. One is signal transduction from the environment through the sensory system to the genome, mediated by the neuroendocrine system and their associated hormones that function as both transcription factors and neuro-transmitters. Secondly, during the process of direct induction, environmental factors interact directly with the cell where they can either activate or repress signal transduction cascades that active gene expression. Thirdly, following environmental induction epigenetic molecular mechanisms alter gene expression by chemically modifying the DNA nucleotide bases or the DNA chromatin structure. DNA methylation and histone deacylation repress gene expression by blocking access to the DNA by transcription factors, while the opposite mechanisms of demethylation and acetylation render the DNA active by allowing certain transcription factors with promoter binding capacity to recruit the transcriptional machinery to the DNA.

Chromatin is the chromosomal complex made up of DNA and histone proteins that enables DNA to be tightly packaged into the nucleus and helps to control transcriptional access to DNA. Originally thought to be a rather structurally static complex, chromatin 
has been shown to be part of a very flexible and dynamic mechanism of precise transcriptional regulation. Accordingly, chromatin remodeling such as methylation (DNA and proteins) and acetylation (protein) does not only occur in early development but can happen later in life, thus providing a mechanism through which the environment sculpts the genome and affects the phenotype throughout the whole life cycle. Hence the response of the 'epigenome' to environmental influences is a biological mechanism that serves as a medium for the adaptability of the genome to altered environments during life.

There are at least four different aspects of how this epigenetic control of gene expression relates to development and learning: 1) In the course of morphogenesis and psychogenesis undifferentiated and totipotent stem cells divide into pluripotent cells that are able to react to environmental signals by remodeling chromatin to change the cell's gene expression; during this process these originally pluripotent cells develop into fully differentiated cells identified by their individual 'epigenetic code' and its associated differential gene-expression pattern. These relatively stable alterations of the chromatin structure are one of the cell's main memory mechanisms by which they inherit and maintain their differentiated phenotype.

2) Epigenetic changes are also the main mechanisms underlying the process called 'fetal programming, "the concept that epigenetic factors in the inauterine environment have a profound effect on the trajectory of prenatal development" (Nathanielsz and Thornburg 2003) that can lead to lasting effects of neonatal experience on adult physical (cardiovascular, metabolic diseases) and psychological (stress reaction, neural plasticity, depression, schizophrenia) phenotype. There is a wealth of experimental evidence that relates maternal care in mammals to epigenetic changes of genes in the cells of selected neural systems. For instance, increased NMDA receptor expression can influence hippocampal synaptic development and function, which then translates into differential spatial learning and memory abilities (Meaney 2001). In other words, there exists a developmental need for epigenetic mechanisms to allow formation of a normal nervous system. 
3) Beyond these two developmental aspects, the roles of epigenetic mechanisms in cognitive processes throughout life, such as learning and memory formation, are becoming increasingly appreciated. These include influences on associative fear conditioning, extinction of conditioned fear, latent inhibition, spatial learning and memory, and memory recovery. Epigenetic mechanisms have also been implicated in the positive effects of environmental enrichment on memory capacity. It can be postulated that DNA methylation/histone modification-mediated gene regulation is not only important for neural cell differentiation but also crucial for synaptic plasticity and highorder cognitive functions such as learning and memory, especially the formation of longterm memories.

Together these studies demonstrate that experience, activity, and neurotransmitterdependent activity increases histone acetylation and DNA methylation and that both are required for learning and memory. Indeed, there seems to be a dynamic balance between inhibition of a memory suppressor gene (protein phosphatase-1) and induction of a memory enhancer gene (reelin), antagonistically driven by increased states of DNA methylation and histone acetylation, respectively (Miller, Campbell, and Sweatt 2008; Noh et al. 2005).

The finding of specific types of memories associated with specific patterns of histone modifications suggests the intriguing possibility for a type of epigenetic "code for memory formation" (Wood, Hawk, and Abel 2006). In general, the formation of longterm memory requires NMDA-receptor-dependent synaptic transmission. However, different types of long-term memory seem to be associated with distinctive kinds of epigenetically induced modifications of the genetic material: Acetylation of hippocampal histone $\mathrm{H} 3$ but not $\mathrm{H} 4$ is significantly increased in the hippocampus after an animal is trained with a contextual fear conditioning paradigm. A different form of long-term memory, latent inhibition, was associated with altered acetylation of histone H4, whereas $\mathrm{H} 3$ acetylation was unaltered by this paradigm (Chwang et al. 2006). 
4) If an environmentally produced sensory input induces a change in behavior that persists beyond the presence of the original stimulus, we are speaking of memory. Such a notion of memory applies not just to neural systems, but also to cells that use (among other mechanisms) chromatin modifications to maintain changes of gene expression through cell divisions for the remainder of a cell's life. Paradigmatically, learning is understood as a usually adaptive, neural response to an input (an external stimulus or the organism's own behavior) in which the input-response relation is memorized. The recall of these memorized relations can later be the basis of a more effective response. It has recently been suggested that this very general characterization of learning applies not only to neuronal systems but also to cellular responses that are based on epigenetic mechanisms of cell memory (Ginsburg and Jablonka 2009).

The extensive interplay between epigenetic mechanisms and learning is well enough established that it is no longer adequate to ignore it, pleading that it's too complex to consider or outside the scope of traditional learning experiments and theory.

\section{Learning and the provisioning of experience as (part of) development}

As we stated at the outset, our objective is to integrate the idea of learning into a wider concept of experience. Specifically, in a systems view of development, learning may appear as just one among many processes in which experience influences the phenotype in general and behavior in particular. Experience affects behavior on many time scales. Even the most fleeting behavioral effects involve gene regulation and expression, but there may be no lasting effects unless the experience is repeated or other conditions coincide to shift the system into a new, relatively stable region of its phase space. Some experiences or combinations of experience, however, produce long lasting changes in the systems' dynamics, and when such changes are (typically) adaptive, we may label them as either development or learning.

But our use of the phrase 'development or learning' is ambiguous. It could mean that these are two fundamentally different kinds of processes that happen to have a similar 
temporal relationship to experience: relatively long term, typically adaptive effects resulting from interactions with contingent aspects of the extracellular environment. Or, it could mean that the development and learning can be more tightly assimilated to one another. Not learning and development, but learning as development. It is this latter interpretation that we wish to defend, if only for the sake of forcing a reconceptualization of a crude dichotomy between these terms.

To begin, we start with a relatively uncontroversial description of development as the process of organismic transformation from a single cell to a differentiated, structured entity. Because this characterization of development tends to suggest a material or anatomical conception of the organ or organism, it can seem like a category mistake to force learning into the same mold. However, it is important to realize that learning is a specialized process of (typically neural) differentiation and structural change that supports (adaptive) modification of behavior by experience. From this it follows that learning is a kind of developmental process: i.e., learning as development. As we have already indicated in connection with bacterial development, we think that this assimilation of learning to development is no mere metaphor: The processes underlying bacterial development and neural modification during learning are evolutionarily conserved to a surprising degree.

We are also willing to go quite far in the other direction, assimilating development to learning. Many if not all biologically significant developmental processes produce lasting changes in behavior as a function of experience. Even something as directly anatomical as limb development has behavioral consequences. Given one standard conception of learning as change of behavior as a function of experience, one may conclude that development is a kind of learning process. It might be objected that this conception of learning is excessively behavioristic --- better definitions involve acquisition of knowledge, or other mental structures. However, in our view, such 'knowledge' is itself biologically insignificant unless it results in behavioral change. 
Several investigators have used the new framework of the developmental niche as one way to go beyond both nativist and empiricist oversimplifications of ontogeny and to highlight how learning processes are part of species-typical and individual development. Jeff Alberts conceptualizes the development of the rat in terms of four consecutive ontogenetic niches through which the pup passes on the way to adulthood (Alberts and Schank 2006). Common to each niche are channels of sustenance for the developing organism, such as nutrients, warmth and insulation, behavioral and social stimuli. The ontogeny of species-typical rat behavior is directed by olfactory cues that are provided by the different stages of the ontogenetic niche. For example, in the second stage, immediately postnatal, olfactory cues on the dam's nipples guide the pup's attachment and suckling. The pup's developing sensoria learn to recognize the odor for the nipple through chemical cues in the amniotic fluid provided by the prenatal 'uterine niche'. The spread of amniotic fluid after birth over the dam's body bridges the pre- and post- natal niches of the pup.

Another example of how the rat's developing niche affords the necessary experience for the developing pup is the 'huddle'. Huddling is an important, species-typical behavior of the rat exhibited from day 15. Filial huddling preferences are mediated by learned olfactory cues. The olfactory-guided species preference is induced by thermotactile stimulation provided by the 'natal niche'. Alberts notes: "Again we find a stereotyped, species-typical, developmentally-fixed behavior is learned, with all of the key components $[\ldots]$ existing as natural features of the ontogenetic niche. ... Specific features of these [nurturant] niches elicit specific reactions and responses in the developing offspring. These reactions and responses constitute conditions sufficient for the formation of a learned association and, as a result, the differentiation of behavior. ... The utter reliability of the ontogenetic niches and the affordances that exist in each are inherited as surely as are genes" (Alberts 2008).

Meredith West and Andrew King have shown over many decades of painstaking research that a nest parasite, the Brown-headed Cowbird, is not a paradigm example of a 'hardwired' species, as normally assumed. If there is a 'safety net' it is not in a 'genetic 
program' but in the social structure of the flock. An individual cowbird's niche is defined by his or her position within the flock, which "gates' what is "bioavailable" to be culturally transmitted or learned throughout the lifespan. According to West and King the developmental system is designed to be as open as ecologically possible. To that effect evolution has trusted an exogenetic developmental niche to transmit information that is vital to cowbird reproduction from one generation to the next (West and King 2008). "It's the dependablility of the niche in delivering certain resources to the young that makes it a legacy. They inherit the senses and the surrounding to find what they need. [Therefore] ask not what is inherited by genes, but what genes inherit" (West, King, and Arberg 1988, 46; West and King 1987). One of their important claims is that the ontogenetic niche gates what is available to be learned, in other words what really matters is the bioavailability of stimulation and experience rather than simple exposure.

Many more examples of the way in which developmental niches provide for the reliability of encountering experiences necessary for normal development could be provided were there space to do so. Such examples would include human language learning, food and habitat imprinting in insects (oviposition); maternal care and stimulation for neural development (sexual behavior and fear reaction in rats; learning disposition in chickens).

\section{The development of learning}

There are some quite straightforward reasons why a more developmentally sensitive approach to animal learning is useful. It may help to uncover age-related behavior differences as well as age-related changes in learning that subjects bring to tasks, and to control for, or even exploit, the effects of earlier experiments with the same subjects. Further interesting questions concern whether mechanisms and content of learning change ontogenetically, and if so, what this can tell us about the generality of learning mechanisms in adults. How are experiential regulation of brain development and general learning mechanisms related? Do developing and mature brains share the same information storage mechanisms or does neural plasticity in early life interfere with the 
processes of learning and memory (Shair, Barr, and Myron 1991, chapters 1, 6, 14, and $15) ?$

A developmental approach to forms of learning and memory in Aplysia helped to differentiate a novel inhibitory process that is often masked by sensitization in the adult, and two different forms of response facilitation, which emerge at different developmental times. Dishabituation and sensitization differ in fundamental ways, such as their developmental timetable, their time of onset, and their stimulus requirements. The investigators therefore concluded that a formerly held, simple dual-process view is inadequate to the features of these two kinds of nonassociative learning processes (Stopher et al. 1991).

\section{The quest for new distinctions}

Our deliberate attempt to erase long-held dichotomies and boundaries doesn't deny the existence of distinctions. Drawing useful distinctions is an important part of the scientific process of categorization, but sometimes one has to let go of long-held beliefs in order to cast new light on an issue, in order to see general principles and continuities instead of clear cut distinctions. Understanding development as the contingent process of construction as outlined above helps to overcome the unscientific dichotomies of nature versus nurture, instinct versus learning or innate versus acquired, and replaces them with scientifically more meaningful and fruitful distinctions. As Lenny Moss puts it:

What the sad endurance of that tired old dichotomy consisting of (conflated) genes and (ill-defined) environment has helped to obscure, are the many levels of biological ordering that mediate between individual molecules and whole developmental systems. To give up the preformationist umbilical cord is not to drop into an abyss of limitless complexity but rather to remain empirically open to discovering what levels of biological ordering is most relevant for one's explanatory purposes (Moss 2001, 91). 
Such distinctions need to rest on a deep analysis of the causal roles played by the diverse developmental resources within the ontogenetic process. The causal role of 'genes', the coding sequences in the DNA sequence, is the 'causal specificity' of the linear sequence of gene products. However, there are cellular processes that change the original coding sequences in reaction to the external environment and conditions within the cell, such as alternative RNA splicing or RNA editing. Hence the molecules that provide 'causal specificity' to these sequence-modifying processes share the causal role of genes. Another causal role, 'activator', is shared by a range of diverse proteins. These same proteins may fulfill other causal roles, such as 'inhibitor', depending on the context in which they find themselves and to which group of interacting molecules they are recruited. Activators recruit another large group of diverse proteins that share the causal role of 'transcription factors', which recruit one of the diverse enzymes polymerase that starts DNA transcription.

An analysis of the causal role of factors reveals a hierarchy of functions, and how many factors share a single causal role depends in part on detailed we describe this role

Developmental resources play a range of causal roles. Many cases cited in the 'eco-devo' literature show that the 'instructive' role can be carried out by environmental factors while the underlying genes play merely a 'permissive role, e.g. in cases of polyphenisms. Examples include the temperature- or context-dependent sex determination of many reptiles, fish and worms. This context-dependency of the morphological and behavioral phenotype is a "necessary condition of integrating the developing organism into its habitat" (Gilbert 2003, 98). A developmental systems view promotes another distinction: between resources that are 'reliably reproduced' (therefore inherited) from one generation to the next and those that are 'novel' or 'contingent'. Within inherited resources, the mechanism of transmission may be 'sample-based' or 'informational', or may serve the role of increasing developmental 'plasticity' or 'canalization' of phenotype. For any causal role at the center of an investigation, there will be a range of factors that are 'causally specific' with respect to it, and others that are mere background conditions. But 
whatever role is being investigated, hardly ever will it divide developmental resources neatly in genetic and non-genetic (Griffiths and Gray 2005).

\section{Conclusion}

The last decade has witnessed enormous scientific advances in genomics, systems biology, social neuroscience, evolutionary, and ecological and developmental biology, introducing notions such as 'evo-devo', 'eco-devo', phenotypic plasticity, niche construction, extragenetic inheritance, developmental systems theory. In light of these advances it is no longer reasonable to defend either gene-centered, pre-deterministic explanations of behavior or strongly environmentalist explanations. Nature and nurture are not separable entities with nature as the a priori plan and nurture as the contingent experiences shaping the outcome of the plan's execution. Instead, we now know that every trait develops out of the nonlinear interactions among a range of very diverse developmental resources. We argue that, for the purpose of explaining the behavioral and cognitive capacities of animals, these are not usefully divided into genetic and nongenetic resources. Behavioral development starts with the environmental regulation of gene expression, and depends upon a range of experiences beneath the skin and above the gene, to construct the stages of sensory and social learning in vertebrates, to the exquisitely sensitive learning capacities of the human brain. 'Nurture' is this ongoing process of development, while 'nature' is the natural outcome of the organismenvironment-system (Oyama 1999).

Our aim in this paper has been to argue that the separation of questions about learning and comparative cognition in nonhuman animals from questions about their development is as untenable as the old distinction between nature as genes and nurture as environment. Too many experiments testing the cognitive abilities of animals are done without fully reporting the developmental backgrounds of the research subjects, let alone systematically investigating the role of a lifetime of experience in the construction of the animals' behavioral-cognitive phenotype. 
We have also argued for a more conceptual point about the assimilation of learning and development. That argument can be summarized as follows:

1. Development is the process encompassing the complete life cycle of organismic transformation from a single cell to a differentiated, structured entity.

2. Learning is a specialized process of (typically neural) differentiation and structural change that supports (typically adaptive) modification of behavior by experience throughout the lifespan of the organism.

3. Therefore, learning is a kind of developmental process: i.e., learning as development.

We advance more tentatively an argument for the identification in the opposite direction, viz.:

4. All developmental processes (that matter biologically) produce a change in behavior as a function of experience.

5. Therefore, development is a kind of learning process.

How might taking development seriously be important to matters of philosophical and scientific interest? In our view, comparative psychology (and the philosophy of animal cognition) is seduced by a facile mapping of the cognitive capacities of animals to the cognitive stages of humans, as if it is meaningful to say that chimpanzees are the cognitive equivalents of two-and-a-half year old children, for example. Likewise, we think that philosophical and scientific energy would be better spent on trying to understand the experiences that are important for individuals of various species to develop a capacity for learning from experience, rather than trying to argue about the extent to which a capacity for imitation is the product of an innate or pre-programmed theory of mind module.

Although we do not have the space to develop these points in detail, we also think that various philosophical attempts to naturalize intentional content embody preformationist assumptions. The major theories of the past couple of decades treat adult concepts as fixed points of meaning. The assumption was explicit in Jerry Fodor's nativism and it appears more subtly in Dretske's early attempts to ground meaning as the stable outcome 
of a discrete pre-semantic learning phase (Fodor 1975; Dretske 1981). While Dretske's account allowed an important role for experience in fixing meanings, it foundered on the impossibility of finding a sharp divide between the pre-semantic phase and the adult stage of fixed meanings. The systems view of development treats learning as one among many processes in which experience influences behavior in a lifelong process of adaptive construction of the phenotype in its environment. This perspective suggests that the existing strategies for naturalizing content are doomed to fail in face of the developmental facts. Any single-factor theory of content will, at best, be a lowdimensional abstraction of what is a much richer set of interactions between organisms and their environments. To some this might suggest an eliminativist stance towards notions such as representation, meaning, and intentional content. Here, however, we do not want to take a stand on this issue, although we believe that low-dimensional abstractions are sometimes important tools for scientific modeling. However, more inclusive and detailed models are the ultimate goal.

A similar understanding of development to the one proposed here had been arrived at independently in one corner of the cognitive science community, specifically among those interested in situated and embodied cognition, most notably the branch called Dynamical Systems Theory. Samuelson and Smith advocate for the dynamical systems perspective when they write, "We believe that in the next century, coupling the dynamics of perceiving and remembering with the dynamics of development will lead us to a more complete theory of knowledge and its development" (Samuelson and Smith 2000, 98).

Our vision of how to integrate the concepts of learning and development is based on a wider understanding of the role of the heterogeneous mix of resources making up 'experience' or 'environment' (Moore 2003). To what extent does the experienced environment correspond to the environment of behavioral development? If experience is defined to involve only what is known through senses, then it is a subset of the latter. A wider conception of developmental environments may include non-obvious influences with no straightforward connection to their effects on the organism. These influences are the object of study in developmental psychobiology but rarely ever investigated by 
comparative psychologists. With the concept of experience playing a central role, a biologically-informed psychology would have as one of its consequences that there would be hardly any features whose development is outside the scope of the psychological sciences. It would not, then, be appropriate to take these features as given. Calling a feature 'innate' or announcing that it 'matures' is simply issuing a "promissory note against future developmental psychology and biology" (Griffiths and Stotz 2000, 38). An elucidation of the developmental cascade by which a behavioral-cognitive capacity develops will contain both biological and psychological factors. It is our contention that any adequately naturalized account of philosophically significant notions such as intentionality, meaning, and knowledge can ill afford to ignore the best going scientific account of an organism's nature.

\section{References}

Alberts, J. R., 2008, 'The nature of nurturant niches in ontogeny', Philosophical Psychology, 21 (3 (Special Issue, Reconciling Nature and Nurture in the study of Cognition and Behavior)):295-303.

Alberts, J. R., and J. C. Schank, 2006, Constructing ontogenetic niches. In: ALife X Conference, Indiana University Bloomington.

Allen, C., J. W. Grau, and M. W. Meagher, 2009, 'The Lower Bounds of Cognition: What Do Spinal Cords Reveal?' In: The Oxford Handbook of Philosophy and Neuroscience, edited by J. Bickle, Oxford: Oxford University Press.

Baker, M. D., and J. B. Stock, 2007, 'Signal Transduction: Networks and Integrated Circuits in Bacterial Cognition', Current Biology, 17 (23):R1021-R1024.

Ben-Barak, I., 2008, Small Wonders: How Microbes Rule Our World, Carlton North, Vic.: Scribe Publication.

Bering, J. M., 2004, 'A critical review of the "enculturation hypothesis": the effects of human rearing on great ape social cognition', Animal Cognition, 7:201-212.

Blumberg, M., 2005, Basic Instinct: The Genesis of Behavior, New York: Thunder's Mouth Press.

Boakes, R., 1984, From Darwinism to Behaviorism, Cambridge: Cambridge University Press.

Burrell, B. D., and C. L. Sahley, 2001, 'Learning in simple systems', Current Opinion in Neurobiology, 11:757-764.

Byrne, R. W., 2004, 'Detecting, understanding, and explaining animal imitation'. In: Perspectives on imitation: From mirror neurons to memes, edited by S. Hurley and N. Chater, Cambridge: MIT Press.

Cacioppo, J. T., and G. G. Berntson, eds. 2004. Essays in Social Neuroscience. Edited by J. T. Cacioppo and G. G. Berntson, Social Neuroscience Series. Cambridge, MA: The MIT Press. 
Call, J., and M. Tomasello, 1996, 'The effects of humans on the cognitive development of apes.' In: Reaching into Thought, edited by A. E. Russon, K. A. Bard and S. T. Parker, New York: Cambridge University Press.

- 1998, 'Distinguishing intentional from accidental actions in orangutans (Pongo pygmaeus), chimpanzees (Pan troglodytes) and human children (Homo sapiens)', Journal for Comparative Psychology, 112:192-206.

Carmichael, L., 1925, 'Heredity and Environment: Are they antithetical?' Journal of Abnormal and Social Psychology, 20:245-260.

Castellucci, V., H. Pinsker, I. Kupfermann, and E. R. Kandel, 1970, 'Neuronal mechanisms of habituation and dishabituation of the gill-withdrawal reflex in Aplysia ', Science, 167 (926):1745-8.

Chwang, W. B., K. J. O’Riordan, J. M. Levenson, and J. D. Sweatt, 2006, 'ERK/MAPK regulates hippocampal histone phosphorylation following contextual fear conditioning', Learning and Memory, 13:322-328.

Dretske, F., 1981, Knowledge and the Flow of Information, Cambridge: MIT Press. Fodor, J. A., 1975, The Language of Thought, New York: Crowell.

Freeberg, T. M., M. J. West, A. P. King, S. D. Duncan, and D. R. Sengelaub, 2002, 'Cultures, genes, and neurons in the development of song and singing in brownheaded cowbirds (Molothrus ater)', Journal of Comparative Physiology, 188:9931002.

Furlong, E. E., K. J. Boose, and S. T. Boysen, 2008, 'Raking it in: the impact of enculturation on chimpanzee tool use', Animal Cognition, 11 (1):83-97.

Gácsi, M., G. B., Z. Virányi, E. Kubinyi, B. Belényi, and Á. Miklósi, Forthcoming, 'Selection for Developmental Shift Explains Dog-Wolf Difference in Utilizing Human Pointing Gestures', PLoSONE.

Gilbert, S., and D. Epel, 2009, Ecological Developmental Biology: Integrating Epigenetics, Medicine, and Evolution, Sunderland, MA: Sinauer Associates.

Gilbert, S. F., 2001, 'Ecological Developmental Biology: Developmental Biology meets the Real World', Developmental Biology, 233:1-22.

- 2003, 'The reactive genome'. In: Origination of Organismal Form: Beyond the Gene in Developmental and Evolutionary Biology, edited by G. B. Müller and S. A. Newman, Cambridge, MA: The MIT Press.

Ginsburg, S., and E. Jablonka, 2009, 'Epigenetic Learning in Non-Neural Organisms', Journal of Bioscience, 34 (4):xxx-xxx.

Gottlieb, G., 2001, 'A Developmental Psychobiological Systems View: Early Formulation and Current Status'. In: Cycles of Contingency: Developmental Systems and Evolution, edited by S. Oyama, P. E. Griffiths and R. D. Gray, Cambridge, Mass.: MIT Press.

Grau, J. W., E. D. Crown, A. R. Ferguson, S. N. Washburn, M. A. Hook, and R. C. Miranda, 2006, 'Instrumental learning within the spinal cord: Underlying mechanisms and implications for recovery after injury', Behavioral and Cognitive Neuroscience Reviews, 5:191-239.

Grau, J. W., and R. L. Joynes, 2005, ' A neural-functionalist approach to learning', International Journal of Comparative Psychology, 18:1-22.

— 2005 , 'Neurofunctionalism revisited: Learning is more than you think it is', International Journal of Comparative Psychology, 18:46-59. 
Griffiths, P. E., 2002, 'What is Innateness?' The Monist, 85 (1):70-85.

$\longrightarrow, 2004$, 'Instinct in the '50s: The British reception of Konrad Lorenz's Theory of Instinctive Behaviour', Biology and Philosophy, 19 (4):609-631.

Griffiths, P. E., and R. D. Gray, 2005, 'Three Ways to Misunderstand Developmental Systems Theory', Biology \& Philosophy, 20 (2):417-425.

Griffiths, P. E., and K. Stotz, 2000, 'How the Mind Grows: A Developmental Perspective on the Biology of Cognition', Synthese, 122 (1-2):29-51.

Herrmann, E., J. Call, M. V. Hernandez-Lloreda, B. Hare, and M. Tomasello, 2007, 'Humans have evolved specialized skills of social cognition: the Cultural Intelligence Hypothesis', Science, 317:1360-66.

Inouea, S., and T. Matsuzawa, 2007, 'Working memory of numerals in chimpanzees', Current Biology, 17 (23):R1004-R1005.

Jablonka, E., and M. J. Lamb, 2005, Evolution in Four Dimenesions: Genetic, Epigenetic, Behavioral, and Symbolic Variation in the History of Life., Cambridge, MA: The MIT Press.

Johnston, T., 2002, 'An early manuscript in the history of American comparative psychology. Lewis Henry Morgan's Animal Psychology', History of Psychology, 5 (4):323-355.

Johnston, T. D., 2001, 'Towards a systems view of development: An appraisal of Lehrman's critique of Lorenz'. In: Cycles of Contingency: Developmental Systems and Evolution, edited by S. Oyama, P. E. Griffiths and R. D. Gray, Cambridge, Mass.: MIT Press.

Jones, S. S., 2005, 'Why don't apes ape more?' In: Perspectives on imitation: From cognitive neuroscience to social science, edited by S. Hurley and N. Chater, Cambridge, MA: MIT Press.

Keller, E. F., 2000, The Century of the Gene, Cambridge, Mass.: MIT Press.

Kumashiro, M., H. Ishibashi, Y. Uchiyama, S. Itakura, A. Murata, and A. Iriki, 2003, 'Natural imitation induced by joint attention in Japanese monkeys', International Journal of Psychophysiology, 50:81-99.

Kuryatov, A., B. Laube, H. Betz, and J. Kuhse, 1994, 'Mutational analysis of the glycinebinding site of the NMDA receptor: structural similarity with bacterial amino acid-binding proteins', Neuron, 12 (6):1291-300.

Lehrman, D. S., 1953, 'Critique of Konrad Lorenz's theory of instinctive behavior', Quarterly Review of Biology, 28 (4):337-363.

$\longrightarrow, 1970$, 'Semantic \& conceptual issues in the nature-nurture problem'. In: Development \& Evolution of Behaviour, edited by D. S. Lehrman, San Francisco: W. H. Freeman and co.

Lewontin, R. C., 2000, The Triple Helix: Gene, Organism, and Environment, Cambridge: Harvard University Press.

Lloyd, E. A., 2004, 'Kanzi, evolution, and language', Biology \& Philosophy, 19:577-588.

Lyon, P. 2006. The Agent in the Organism: Towards a Biogenic Theory of Cognition. $\mathrm{PhD}$ Australian National University.

Maestripieri, D., and J. M. Mateo, 2009, Maternal Effects in Mammals, Chicago: The University of Chicago Press.

Maienschein, J. 2005. Epigenesis and Preformationism. Stanford Encyclopedia of Philosophy, http://plato.stanford.edu/entries/epigenesis/. 
Maturana, H. R., and F. J. Varela, 1980, Autopoiesis and Cognition: The Realization of the Living, New York: Springer.

McGonigle, B., and M. Chalmers, 2001, 'The Growth of Cognitive Structure in Monkeys and Men'. In: Animal Cognition and Sequential Behavior: Behavioral, Biological, and Computational Perspectives, edited by S. B. Fountain, M. D. Bunsey, J. H. Danks and M. K. McBeath, New York: Springer.

McGonigle, B. O., and M. Chalmers, 2001, 'The growth of cognitive structures in Monkeys and Men'. In: Animal Cognition and Sequential Behaviour.

Behavioural, Biological and Computational Perspectives, edited by S. B. Fountain, M. D. Bunsey, J. H. Danks and M. K. McBeath, Boston: Kluwer Academic Publisher.

— 2008, 'Putting Descartes before the horse (again!). Commentary on Penn, D., Povinelli, D.J and Holyoak, K.J.' Behavioral and Brain Sciences, 31 (2):142-143.

Meaney, M. J., 2001, 'Maternal care, gene expression, and the transmission of individual differences in stress reactivity across generations.' Annual Review Neuroscience, 24:1161-92.

Michel, G. F., and C. L. Moore, 1995, Developmental Psychobiology : An interdisciplinary science, Cambridge, MA: MIT Press.

Miller, C. A., S. L. Campbell, and J. D. Sweatt, 2008, 'DNA methylation and histone acetylation work in concert to regulate memory formation and synaptic plasticity', Neurobiology of Learning and Memory, 89:599-603.

Moore, C. L., 1984, 'Maternal contributions to the development of masculine sexual behavior in laboratory rats', Developmental Psychobiology, 17 (4):347-356.

— 2003, 'Differences between organism-environment systems conceived by Lehrman and Gibson: What's in the nest of reciprocities matters', Developmental Psychobiology, 42 (4):349-56.

Moss, L., 2001, 'Deconstructing the gene and reconstructing molecular develomental systems'. In: Cycles of Contingency: Developmental Systems and Evolution, edited by S. Oyama, P. E. Griffiths and R. D. Gray, Cambridge, Mass.: MIT Press.

Mousseau, T. A., and C. W. Fox, eds. 1998. Maternal Effects as Adaptations. Oxford: Oxford University Press.

Nathanielsz, P. W., and K. L. Thornburg, 2003, 'Fetal programming: from gene to functional systems -an overview', Journal of Physiology, 547:3-4.

Newman, S. A., 2003, 'From physics to development: the evolution of morphogenetic mechanisms'. In: Origination of Organismal Form: Beyond the Gene in Developmental and Evolutionary Biology, edited by G. B. Müller and S. A. Newman, Cambridge, MA: The MIT Press.

Noh, J., R. P. Sharma, M. Veldic, A. A. Salvacion, X. Jia, and Y. Chen, 2005, 'DNA methyltransferase 1 regulates reelin mRNA expression in mouse primary cortical cultures', PNAS, 102:1749-1754.

Oyama, S., 1999, 'The nurturing of natures'. In: On Human Nature. Anthropological, Biological and Philosophical Foundations, edited by A. Grunwald, M. Gutmann and E. M. Neumann-Held, New York: Springer.

Oyama, S., P. E. Griffiths, and R. D. Gray, 2001, 'Introduction: What is developmental systems theory?' In: Cycles of Contingency: Developmental Systems and 
Evolution, edited by S. Oyama, P. E. Griffiths and R. D. Gray, Cambridge, MA: MIT Press.

, eds. 2001. Cycles of Contingency: Developmental Systems and Evolution. Cambridge, MA: MIT Press.

Penn, D. C., K. J. Holyoak, and D. J. Povinelli, 2008, 'Darwin's mistake: Explaining the discontinuity between human and nonhuman minds', Behavioral and Brain Sciences, 31 (2):109-129.

Pigliucci, M., 2001, Phenotypic Plasticity: Beyond Nature and Nurture, Syntheses in Ecology and Evolution, Baltimore: The Johns Hopkins University Press.

Robert, J. S., 2004, Embryology, Epigenesis and Evolution: Taking Development Seriously., Cambridge: Cambridge University Press.

Saigusa, T., A. Tero, T. Nakagaki, and Y. Kuramoto, 2008, 'Amoebae Anticipate Periodic Events', Physical Review Letters, 100 (1):018101.

Samuelson, L. K., and L. B. Smith, 2000, 'Grounding development in cognitive processes', Child Development, 71 (1):98-106.

Savage-Rumbaugh, S., W. M. Fields, and T. Spircu, 2004, 'The emergence of knapping and vocal expression embedded in a Pan/Homo culture', Biology \& Philosophy, 19 (4):541-575.

Shair, H. N., G. A. Barr, and H. A. Myron, eds. 1991. Developmental Psychobiology: New Methods and Changing Concepts. Oxford, New York: Oxford University Press.

Shapiro, J. A., 2007, 'Bacteria are small but not stupid: cognition, natural genetic engineering and socio-bacteriology', Studies in History and Philosophy of Biological and Biomedical Sciences, 38:807-819.

Shettleworth, S. J., 1994, 'Biological approaches to the study of learning'. In: Handbook of Perception and Cognition, edited by N. J. Mackintosh, London: Academic Press.

Smith, L. B., and C. Breazeal, 2007, 'The dynamic lift of develpmental process', Developmental Science, 10 (1):61-68.

Spencer, J. P., D. Corbetta, P. Buchanan, M. Clearfield, B. Ulrich, and G. Schöner, 2006, 'Moving toward a Grand Theory of Development: In memory o Esther Thelen', Child Development, 77 (6):1521-1538.

Stopher, M. A., E. A. Marcus, T. C. Nolen, C. H. Rankin, and T. J. Carew, 1991, 'Learning and memory in Aplysia: A combined developmental and simple systems approach'. In: Developmental Psychobiology: New Methods and Changing Concepts, edited by H. N. Shair, G. A. Barr and H. A. Myron, Oxford: Oxford University Press.

Stotz, K., 2006, 'Molecular epigenesis: distributed specificity as a break in the Central Dogma", History and Philosophy of the Life Sciences, 28 (4):527-544.

Tagkopoulos, I., Y. Liu, and S. Tavazoie, 2008, 'Predictive behavior within microbial genetic networks', Science, 320:1313-1317.

Thelen, E., 1995, 'Time-scale dynamics and the development of an embodied cognition'. In: Mind as Motion: Explorations in the Dynamics of Cognition, edited by R. F. Port and T. van Gelder, Cambridge, M.A: MIT Press.

Thorndike, E. L., 1911, Animal Intelligence, Darien, CT: Hafner. 
Timberlake, W., 2002, 'Niche-related learning in laboratory paradigms: the case of maze behavior in Norway rats', Behavioural Brain Research 134, 134:355-374.

Tomasello, M., 1999, The Cultural Origins of Human Cognition, Cambridge, MA: Harvard University Press.

Tomasello, M., and J. Call, 2004, 'The role of humans in the cognitive development of apes revisited', Animal Cognition, 7:213-215.

West, M. J., 2003, 'The case for developmental ecology', Animal Behaviour, 66:617-622.

West, M. J., and A. P. King, 1987, 'Settling Nature and Nurture into an Ontogenetic Niche', Developmental Psychobiology, 20 (5):549-562.

— 2008, 'Deconstructing innate illusions: Reflections on nature-nurture-niche from an unlikely source', Philosophical Psychology, 21 (3 (Special Issue, Reconciling Nature and Nurture in the study of Cognition and Behavior)):383-395.

West, M. J., A. P. King, and A. A. Arberg, 1988, 'The Inheritance of Niches'. In: Handbook of Behavioral Neurobiology, edited by E. M. Blass: Plenum Press.

West, M. J., A. P. King, and M. A. Duff, 1990, 'Communicating about Communicating: When Innate Is Not Enough', Developmental Psychobiology, 23 (7):585-598.

West-Eberhard, M. J., 2003, Developmental Plasticity and Evolution, Oxford: Oxford University Press.

Wood, M. A., J. D. Hawk, and T. Abel, 2006, 'Combinatorial chromatin modifications and memory storage: A code for memory?' Learning and Memory, 13 (21-244).

Zimmer, C., 2008, Microcosm: E. coli and the New Science of Life, New York: Pantheon Books. 